\title{
Research on Evacuation Strategies of Metro
}

\author{
Xiangyang Wan \\ Hubei University of Police, Wuhan, Hubei 430034, China \\ wancooke@sina.com
}

Keywords: Research; Evacuation; Strategies; Metro

\begin{abstract}
The metro is a crowded place, its special structure in the endangered, prone to congestion and trampling, then the metro evacuation and rescue is the primary task. This paper studied the effects of three factors of metro evacuation, and then analyzes the evacuation route and evacuation conditions, finally puts forward the evacuation strategies which the guidance and instruction of evacuation, the tidal control etc., provides the corresponding solutions for metro evacuation.
\end{abstract}

\section{Introduction}

Metro as a specific form of public transport in modern large city which solve transport problem, Its rapid time, large carrying capacity, all-weather service features effectively make up ground traffic congestion, people travel to bring inconvenience. However, due to the limitation of the existing subway tunnel type, such as the running line, special small enclosed space, waiting open and loose management mode, makes the subway once the earthquake, flooding, collapse, fire hazard, explosion, poison gas and other attacks, and even blackouts, accidents such as collision, fault prone to congestion, trampling. So, encounter danger, the first task is to quickly and effectively will be a large number of personnel in the metro and the platform of the evacuation and rescue of the injured, synchronization, which is the study of metro security very important topic.

\section{The Impact Factors of Evacuation}

Metro Evacuation is the time that allowing peoples evacuate in the subway danger yet or not fully threat by using the platform, the station hall aisle, staircases and safety exit space consisting of all the personnel evacuation, safety and quickly withdrawn from the metro station. Although metro evacuation time is not uniform standard, but National Standards of Fire Danger(GB50157-2003) provisions "Entrance stairs and evacuation channel width, should ensure that the fire in the forward peak hour traffic circumstances at the time, 6 minutes to the train passengers and the waiting passengers and staff evacuated." Thus, people can safely evacuate depends on two time: one is the situation to pose a threat to personnel needed time Taset (Available Safe Egress Time), also known as the available safe time; two is required to evacuate personnel to a safe place in time Trset (Required Safe Egress Time), also known as the time required for evacuation. In order to ensure the safe evacuation of personnel, must make all personnel in danger to personnel safety development threat before successfully evacuated to a safe location, namely the request Taset $<$ Trset .

Required Safe Egress Time (Trset). In theory, the evacuation process including found dangerous, personnel evacuation reaction. This time interval is called the alarm time Td; The time which found dangerous to evacuate known as the personnel evacuation time response of $\mathrm{Tr}$; after the 
start, through the corridors, stairs, personnel security exports reached a place of safety, this time known as the evacuation action time Tk. Thus, Trset as above the three part time and, i.e.:Trset $=$ $\mathrm{Td}+\mathrm{Tr}+\mathrm{Tk}$

Td depends on the danger judgment and alarm system. Metro dangers, whether disaster accidents or criminal cases, management all judgment will have a delay, and even some judgment completely failure, such as the terrorist bombing as fire, the mustard gas as a gas leak. This is understandable, after all the danger is often determined by the nature of afterwards; and to the passenger, then choose escape scenarios than choose alarm. In view of the fact that the Td time when it is difficult to determine, normally does not account for Trset.

Tr depends on the Metro Inc's management ability, but the metro a face in the crowd is a loose group heterogeneity, group disorder and limited rational individual focus collision collective escape phenomenon, after all, when the individual psychological correction and collective action regulation is not enough to fire against the crisis occurred, mobility hedging out collective escape behavior is the most reasonable and the most appropriate. In the face of great danger, response time is left to the people is jumping: the lack of restraint mechanisms crowd first knowledge and dull, aware of the danger immediately choose to flee, so Tr basic cannot measure.

Tk depends on the subway structure arrangement and the crowd moving speed. The metro station structure and layout including architectural layout and facility layout, the layout of the building such as metro stations on the stair width, subway line road length; facility layout such as width, subway access gate machine the size of commercial facilities. The crowd moving speed available unit time advance distance to quantify, it is influenced by age, body composition, flow density, law restriction, such as population density is greater, because of the interaction between the body, the crowd more slowly; when the crowd through an entrance or exit, if there is a sequence of moving, can be smooth circulation. Travel faster then the flow is greater. And when the crowd is crowded, then the flow is greatly reduced. This is the so-called "bottleneck"; the whole crowd synchronous received emergency evacuation information, synchronous or in similar time response action, when the exit width limits dense population flow, resulting in mobile intensive crowd formed at the outlet, showing "the characteristics of the arched distribution" etc.. Research shows that the crowded degree of important role in the control of population movement speed, but the degree of congestion available personnel density and flow indicators are described.

Available Safe Egress Time (Taset) . In fact, Taset and Trset are often the same time began, namely the danger was found when it has reached the degree of harm of crowd safety, danger occurs when the crowd began evacuation behavior, that is to say, the evacuation process is dangerous development process, separate the Taset stripping out without what substantive significance. This is because:

1. The huge harm metro accident disasters or criminal cases, such as the subway fire accident, because of the unique structure of the subway tunnel ventilation, resulting in the chimney effect is especially obvious, extremely easy to cause the large crowds choked to death, February 18, 2003 South Korea Daegu city subway fire disaster hair caused 198 deaths and 146 injured, 298 missing is a typical example. So, many metro danger occurs when the Trset is very short.

2. In the dangerous crowd is not out of danger degree of recognition ability, and the accident is more difficult to obtain accurate information, so only aware of danger, who wouldn't take a stopwatch to card Trset and the advent of the end of time, everyone will fling caution to the winds to 
choose to escape. In this case, Trset and Taset for the evacuation of the individual concerned, completely is happening at the same time.

3. The danger is the first metro evacuation and rescue personnel in security, to be determined later, before considering the disposal of dangerous situations, that is to say, the danger can be a very long period of time, the time is divided into danger occurs, Trset, cause the harm and disposal of dangerous situations, this is not what the actual significance of evacuation. If the Taset and Trset as two independent separate steps, it will produce a "first occurred after the danger, danger intensifies, then evacuated people" the procrastination delay error thinking.

\section{The Process of Evacuation}

The paths of Evacuation. Prior to assuming the evacuation began, metro staff distributed in a train compartment, the platform, the station hall etc.. As the evacuation of personnel evacuation began to leave their home space, through a carriage, platform, staircase, hall of station, subway exports evacuation space, transfer to a safe place. In the three categories of staff the station hall, platform, the carriage, the evacuation route respectively:

1. Hall Station staff can directly from the station hall evacuated to safety exit;

2. On the stage of the first arrival hall staff evacuation from the platform, and then by the station hall evacuated to safety exit;

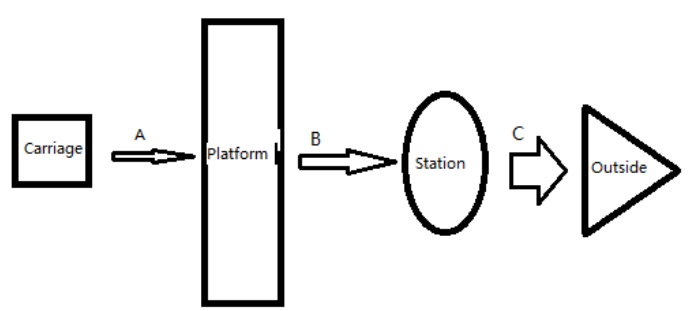

3. Inside people must first start from the inside evacuation to the platform, and then from the platform to the station hall evacuation, finally from the station hall evacuated to the safety of subway exit. In addition, when the subway cars stuck in orbit, inside the staff only first along the tunnel to the ends of the evacuation, because is unable to determine the carriage stays section, in the absence of signs under the guidance, in accordance with the "into the same" memory law, passengers generally choose from starting the evacuation site direction.

Therefore, the subway the whole evacuation space can be simplified as the carriage, platform, the station hall, safety export 4 units, walkways and train compartment door (A), the platform and the platform to the station hall corridor stairs (B), the station hall corridor and the station hall to a safe exit stairs (C) of the 3 evacuation channel.

The Conditions of Evacuation. Although the subway passengers to loose type groups, impulsive and take a hint, but it has a strong psychological conformity, can be treated as a special group, that is, any unit or channel within the population can be considered as a whole, assuming that the unit (or channel) all staff have their own evacuation out, but with the same the characteristics of.

1. Before the start of the personnel evacuation, according to the different density distribution in different units, the stairs without the guidance of personnel. A crowd gathered to British security "green guide book" to $0.25 \mathrm{~m}^{2} /$ Person as the qualification of crowd density. In contrast, Wuhan Metrlo Inc with $0.75 \mathrm{~m}^{2} /$ Person as the limit value is too broad and inconsistent with the actual passenger flow. Although the actual metro crowd dense area mainly in the compartment, the 
platform, the ticket office and import and export, but the most dangerous is the carriage and platform, so the two evacuation distances, the largest evacuation difficulty.

2. The first to reach the safety exit of people not only lies in the location advantage and the advantage of the body, but also according to "crowd action rules with import and export", choose the most familiar with the (best) channel to evacuate. Assuming the indoors and stairs are not blocked, which through the gate time regardless of the stairs, through time as a single man up the stairs walk time.

3. Safety evacuate all personnel in the compartment of the train, must pass through the door, through the station, walk to the station hall, finally out of the station, the desired walk farthest personnel to door time is the most long time. According to the "norms" of Metro Design and measured, the metro train each gate width of 1.5 meters, set emergency metro door crowd flow coefficient 4/3 person / s, so the second out of two individuals from the metro car. In the case of safety isolation door, from the metro car evacuation have this tract isolation door, if the door and metro car door dislocation, will greatly increase the difficulty of personnel escape.

4. On the stair width is the metro most popular construction design which only one on the stairs down and one of the way for elevator. In the ordered the evacuation process, whether the lift should be opened (of course is to convert the station to a direction) is a quite controversial. According to the pedestrian determination, the elevator speed is less than one for speed, but in the same to the elevator to walk on, its speed is certainly faster, so in the case of conditions (many underground dangers accompanied blackout), or suggest to open the elevator. By actual observations, the crowd in the stair exit basic semicircle distribution (Arch Phenomenon), such as W is set as a stair exit width, L crowd of stair exit side area of maximum length, then exit stairway region crowd accounts for the area of $\mathrm{A}=\frac{1}{2} \pi\left(\mathrm{L}+\frac{\mathrm{W}}{2}\right)^{2}$. Later people applied force (pressure big) to prepare to enter the front stairs person (small surface stress), easily at the stairs a stampede.

5. The whole evacuation link constrained by the slowest unit, namely "bucket principle", appearing in the compartment door, stair and brake machine. In addition, complex building design of similar honeycomb like also restricted the evacuation time. If the I channel is the most slow evacuation channel, then the evacuation time is: $\mathrm{T}=\mathrm{Ta}+\mathrm{Ti}+\sum_{\mathrm{i}}^{\mathrm{n}} \mathrm{Tb}$. In the formula, Ta is the first person through the I channel Ti evacuation time; I channel time for all staff; $\mathrm{Tb}$ is the last person through the I channel time.

\section{The Strategies of Evacuation}

The Guidance of Evacuation. 1. Information Transmission. Such as subway each place instructions, temporary prepare evacuation slogans, site speakers broadcast, lighting tips.

2. Staff Guidance. As the lead staff, to guide the direction of evacuation route instructions, on-site civilian dress display.

3. Rescue Instructions. Rescue workers often escape and evacuation direction contrary to the crowd, especially in crowded, dark, smoke and other extreme conditions, some people search and rescue personnel may give up escape see, might follow the rescue personnel reverse marching, these non rational behavior must be corrected in time.

The Instructions of Evacuation. 1. Set Up Export. The crowd into the MTR generally need a period of time, but the evacuation is required in the completion of the moment, so it should be more than the import export quantity. But the subway because of limited environment, often import export, 
even because of the need for credit card settlement, exports less than imports, which requires timely conversion in evacuation entrance. Subway gate should be fully open during the evacuation, credit card machine that turn gate type traffic too low ability, all subway stations no longer upgrade card machine for best opening and closing type. In addition, to do the export instructions, such as signs, lighting, noise, smoke, smell.

2. Widen The Stairs. In the situation of personnel flow is certain, stair evacuation ability mainly restricted, stair width at this time, in order to reasonably, scientifically deal with the station and effective emergency evacuation staircase width of this contradiction, the key is to solve the reasonable design of the stairs.

3. The Road Divides. The usual fixed facilities can use water horse, fence separated access roads, should also be in the subway station, the subway hall on the ground with striking paint color, arrow indicating that path.

Tidal Control.1. Batch Release. Tidal control requirements to batch release in the import and export. In the passenger peak, such as work on the stage, we must set the gate threshold control flow of people, or pause stop flow, or batch ticket release.

2. Appropriate Retention: import and export general relatively narrow, persons can be retained in the import buffer waiting ticket. At present, the city metro transfer stations generally have more business district (commercial paving), can use appropriate means to guide the peak travel passengers to the business district.

3. Control Density. Reasonable density action area people can be sure that does not happen because of congestion, congestion carriage and platform, in the ultra density situation, immediately stop the sale of tickets, passenger station stop, and advised passengers to leave the station, take the other way.

\section{References}

[1] Still G K. Crowd Dynamics . Coventry, UK:University of Warwick, 2000.

[2] Togawa K. Study of fire escapes basing on the observations of multiple currents. Japan: Building Research Institute, 1955.

[3] Gaden E.R., Owen M., Gwynne S. Principles and Practice of Evacuation Modeling. CMS Press, London SE18 6PF, 1997.

[4] http://metro.tehran.ir/

[5] Lines 3 and 4 of Tehran Subway Rapidly Developing. Payvand Iran News. 15 December 2010. Retrieved 2014-04-23.

[6] Leveson, N.G. Software Safety. Computing Surveys 18: pp. 125-163, 1986.

[7] Goddard, P.L.: Software FMEA Techniques. In: Proceedings of Annual Reliability and Maintainability Symposium, Los Angeles, CA, pp. 118-123 (2000)

[8] Ericson, C.A. Hazard Analysis Techniques for System Safety. Wiley Interscience, 2005. 